\title{
Long-range Effect of Bromine in the Deprotonative Metalation of Aromatic Compounds
}

\author{
Florence Mongin* \\ Dedicated to Professor Manfred Schlosser
}

\begin{abstract}
Deprotonative metalation has been largely used to functionalize aromatic compounds. The efficiency of such reactions, as well as their regioselectivity, depends on the substituents connected to the rings. In contrast with other groups such as fluorine and methoxy, bromine exhibits a long-range acidifying effect. Here we try to depict this particular effect of bromine through different examples in which deprotometalation takes place at a remote position.
\end{abstract}

Keywords: Acidity · Aromatic compounds · Deprotonative metalation · Long-range effects · Substituent effects

Among the existing methods to functionalize aromatic compounds including heterocycles, deprotonative lithiation followed by reaction with electrophiles has been widely used, in particular because of its high regioselectivity.[1] The reactivity of the aromatic substrates involved in this reaction, as well as the regioselectivity of the reaction, largely depends on the substituents connected to the ring.

Among the different ortho-directing groups that can be employed in aromatic deprotonative metalation, bromine is far from the best. Indeed, if its ability to acidify the adjacent hydrogens is good, both from a kinetic and a thermodynamic point of view, ${ }^{[2]}$ the ortho-bromoarylmetals formed are prone to benzyne formation. Such a limitation can be overcome either by using lithium-metal bases such

${ }^{\star}$ Correspondence: Prof. F. Mongin Chimie et Photonique Moléculaires Institut des Sciences Chimiques de Rennes UMR 6226, Université de Rennes 1-CNRS Bâtiment 10A, Case 1003, Campus de Beaulieu 35042 Rennes, France

E-mail: florence.mongin@univ-rennes1.fr as TMP-zincate $\left({ }^{t} \mathrm{Bu}_{2} \mathrm{Zn}(\mathrm{TMP}) \mathrm{Li}\right.$, TMP = 2,2,6,6-tetramethylpiperidino), ${ }^{[3]}$ or using in situ electrophilic trapping, ${ }^{[4]}$ or even in the presence of another substituent (e.g. $\mathrm{CF}_{3}^{[5]}$, capable of stabilizing the arylmetal compound. Nevertheless, if bromine is not the best ortho-directing group, it is useful as a meta- or even para-directing group. Herein, we showcase selected deprotometalation reactions in which bromine exhibits such a long-range acidifying effect.[6]

To explain how substituent effects (e.g. acidifying effect) propagate on benzene from the ortho to the meta and to the para position, it has been suggested that two kinds of electronic perturbation operate simultaneously: (i) the inductive effect due to the electronegativity of the hetero-element connected to the ring (such a $\sigma$-polarization diminishes with the distance from the electron-withdrawing substituent) and (ii) the modification of the $\pi$-electron cloud ( $\pi$-polarization) either through aspiration (in the case of a tetravalent and electron-deficient element connected to the ring such as $\mathrm{CF}_{3}$ ) or through repulsion (in the case of a lone-pair containing element connected to the ring such as $\mathrm{F}$ and $\mathrm{OMe}) .{ }^{[7]}$

On aromatic compounds, fluorine enhances the acidity of neighboring hydrogens by the inductive effect (through the $\sigma$-bond) but not by aspiration of the $\pi$-electron cloud. In contrast, due to increased bond lengths, the heavier halogens can modify the $\pi$-electron density of the ring. Indeed, its flow is possible toward the highly polarizable halogen ( $\sigma / \pi$ coupling). This makes chlorine and bromine good long-range electron attractors. ${ }^{[8]}$
Also due to their longer bond, the heavier halogens have a weaker donor capacity than fluorine when present as arene substituents (poorer $\pi$-n overlap). Thus, in contrast to fluorine and other groups (e.g. alkoxy), chlorine and, above all, bromine do not exhibit donor/acceptor dualism. ${ }^{[8]}$ This feature makes bromine at the origin of a specific behavior when used as a substituent in deprotonative metalation of aromatic compounds. It is worth noting that only lithium (or lithium-metal) dialkylamides can be used to effect such reactions, as organometals (and, in particular, polar alkylmetals) can cause bromine/ metal exchange.

\section{Long-range Effect of Bromine in the Deprotometalation of Benzenes}

The long-range acidifying effect of bromine can be easily evidenced from two experiments. If an equimolar mixture of fluorobenzene (1a) and 1,3-dibromobenzene (2a) is treated with 1 equiv. of LiTMP in tetrahydrofuran (THF) in a competitive reaction, the dibromide $\mathbf{2} \mathbf{a}$ is the only substrate converted, as shown by trapping with carbon dioxide. ${ }^{[9]}$ This result shows that two bromo groups are stronger orthodirecting than one fluoro. However, when submitted to the same conditions, 2,4-dibromo-1-fluorobenzene (3a) reacts to afford 3,5-dibromo-2-fluorobenzoic acid $\mathbf{3 b}$ in $82 \%$ yield (Scheme 1). ${ }^{[10]}$

1-Bromo-2-fluorobenzene (4a) and 1-bromo-4-fluorobenzene (5a) can be functionalized next to fluorine upon consecutive treatment with LiDA (DA = diisopropylamino) in $\mathrm{THF}$ at $-75{ }^{\circ} \mathrm{C}$ and dry 


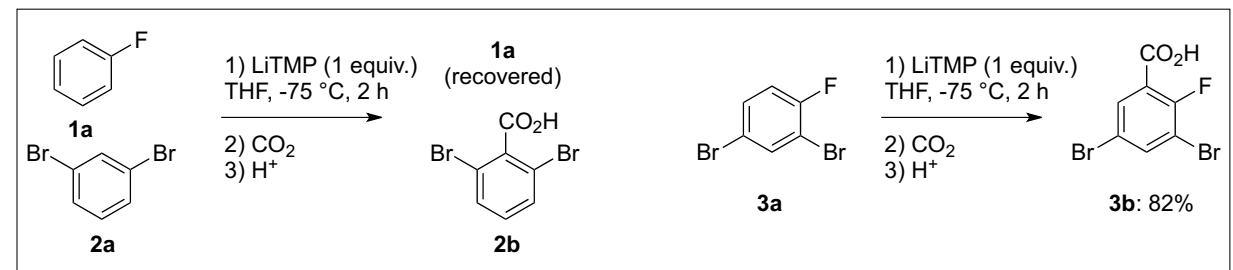

Scheme 1. Reactions demonstrating the long-range acidifying effect of bromine.

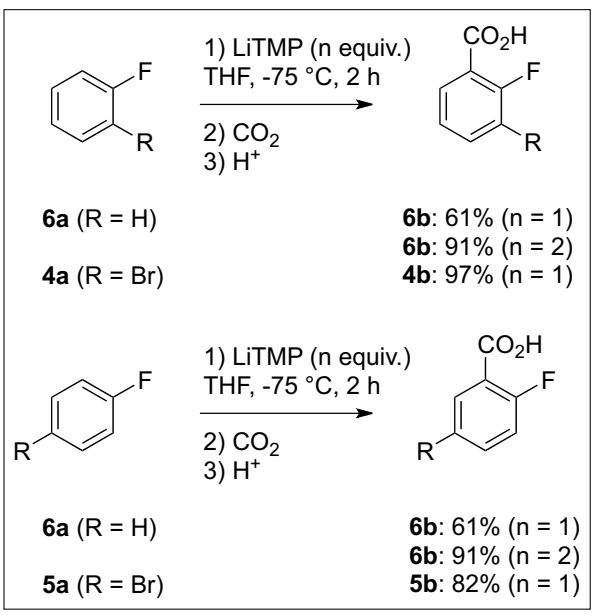

Scheme 2. Deprotonative lithiation of 1-bromo2-fluorobenzene and 1-bromo-4-fluorobenzene compared with that of fluorobenzene.

ice. In the former reaction, 3-bromo-2-fluorobenzoic acid (4b) is the only product, isolated in $73 \%$ yield. ${ }^{[11]}$ In the latter reaction, 5-bromo-2-fluorobenzoic acid (5b, formed in $72 \%$ yield) is accompanied by traces of 2-bromo-5-fluorobenzoic acid. ${ }^{[12]}$ Using LiTMP leads to improved yields, $97 \%$ and $82 \%$ respectively, and regioselectivity. ${ }^{[10]}$ To identify a possible effect of bromine in such reactions, fluorobenzene (6a) was similarly reacted with LiTMP (1 equiv.) in $\mathrm{THF}$ at $-75^{\circ} \mathrm{C}$ for 2 hours before quenching. Under these conditions, 2-fluorobenzoic acid $(\mathbf{6 b})$ was obtained in a $61 \%$ yield, lower than those obtained from the meta-bromo substituted derivatives; a high yield $(91 \%)$ could be reached, but by employing 2 equiv. of base (Scheme 2). [9]

When reacted with a lithium amide at low temperatures in THF, 1-bromo-4-chlorobenzene (7a) gives a mixture of 5-bromo-2-chlorophenyllithium and 2-bromo5-chlorophenyllithium, as demonstrated by subsequent trapping with carbon dioxide. After deprotonative metalation for 2 hours at $-100{ }^{\circ} \mathrm{C}, 5$-bromo-2-chlorobenzoic acid (7b) and 2-bromo-5-chlorobenzoic acid $(\mathbf{7 b}$ ') are respectively formed in 24 and $17 \%$ yield using LiDA, and 29 and $4 \%$ yield using LiTMP (Scheme 3). [13] Chlorobenzene and bromobenzene cannot afford the corresponding carboxylic acids in similar yields. Indeed, only traces of 2-chlorobenzoic acid are obtained by using LiTMP in THF for 2 hours at $-100{ }^{\circ} \mathrm{C}$ before subsequent carboxylation ${ }^{[9,14]}$ whereas bromo- benzene fails to yield 2-bromobenzoic acid due to degradation whatever the conditions used. ${ }^{[9,15]}$ This result shows that chlorine and bromine, even when located at a position meta to the deprotonation site, exhibit a stabilizing effect. In addition, this regioselectivity is not due to a higher orthodirecting power of chlorine over bromine (these effects are similar), but rather arises from a slightly higher meta-acidification of bromine over chlorine. Such a claim can be deduced from a recent article on the relative thermodynamic stabilities between different aryllithiums (Table 1).[2,16]

Owing to this long-range acidifying effect, 1,4-dibromobenzene (8a) (but not strates; $\Delta \mathrm{G}^{\circ}\left(\mathrm{kcal} \mathrm{mol}^{-1}\right)=0.9067 \times\left(\lg K_{\mathrm{x}}-\lg K_{\mathrm{H}}\right)$. bromobenzene) can be deprotolithiated in THF using LiTMP at $-75^{\circ} \mathrm{C}[17]$ or $-80{ }^{\circ} \mathrm{C}$ for $40 \mathrm{~min}$, as evidenced by subsequent reaction with various electrophiles. 2,5-Dibromophenyllithium can be stored at this temperature for at least 1 to 2 hours before degradation (darkening), the latter occurring at temperatures above -75 to -70
${ }^{\circ} \mathrm{C} .{ }^{[18]}$ After interception with carbon dioxide and acidification, the functionalized derivative $\mathbf{8 b}$ is isolated in $84 \%$ yield; using the slightly weaker base LiDA instead of LiTMP affords the same benzoic acid in $68 \%$ yield. Iodine proves to exhibit a similar long-range acidifying/stabilizing effect, as shown in Scheme 4. ${ }^{[18]}$ Provided that the reaction temperature with LiDA is maintained at $-85^{\circ} \mathrm{C}$, extension of the reaction to 2,5-dibromoanisole is possible, giving 2,5-dibromo-3-methoxybenzaldehyde in a moderate $47 \%$ yield after DMF quench and hydrolysis. ${ }^{[19]}$

Similarly, 2- and 4-bromobenzonitrile (10a and 11a) benefit from the long-range meta-acidifying effect of bromine. In contrast with bare benzonitrile, both substrates can be converted to stable lithio derivatives at the position ortho to nitrile when treated with LiTMP in THF at $-80^{\circ} \mathrm{C}$. Such a result can be evidenced by subsequent derivatization to the corresponding boronic acids $\mathbf{1 0 b}$ and $\mathbf{1 1 b}$ by trapping with trimethylborate followed by hydrolysis (Scheme 5). ${ }^{[18]}$

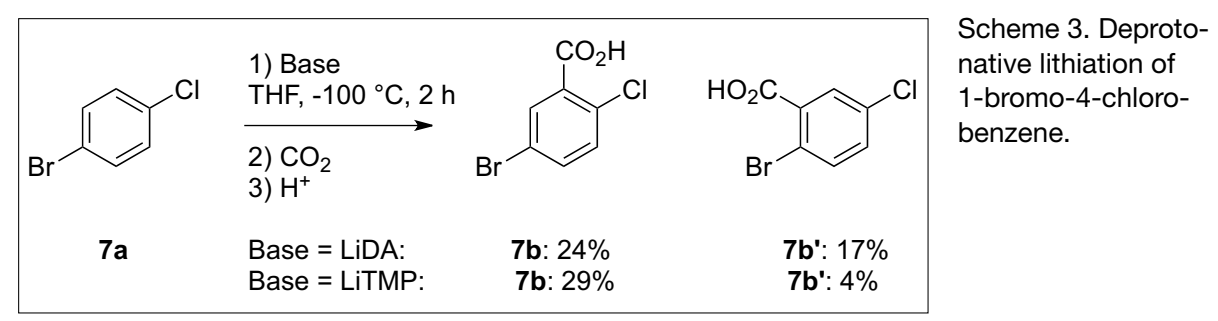

Table 1. Substituent effects on the equilibrium positions between different aryllithiums (prepared using LiTMP, THF, $-75^{\circ} \mathrm{C}$ ): thermodynamic stabilities relative to the unsubstituted lithiated sub-

\begin{tabular}{|l|l|l|l|}
\hline & \multicolumn{1}{|c|}{} \\
\hline $\mathrm{X}$ & & & \\
\hline
\end{tabular}

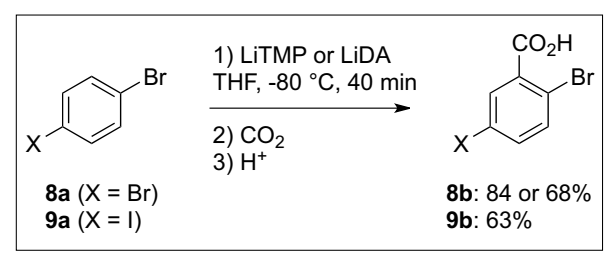

Scheme 4. Deprotolithiation of 1,4-dibromobenzene and 1-bromo-4-iodobenzene. 


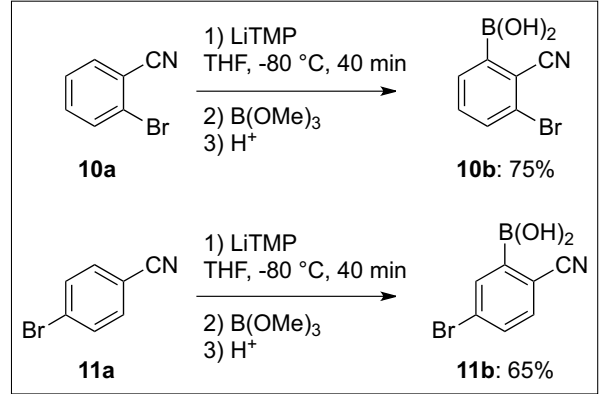

Scheme 5. Deprotolithiation of 2- and 4-bromobenzonitrile. using LiDA in the presence of chlorotrimethylsilane as in situ trap (indeed, LiDA reacts with the aromatic halide more rapidly than it does with chlorotrimethylsilane). Nevertheless, a second deprotolithiation-silylation cannot be avoided, leading to mixtures containing both 1,2-dibromo-3-(trimethylsilyl)benzene (12c) and 2,3-dibromo-1,4-bis(trimethylsilyl) benzene $\left(\mathbf{1 2} \mathbf{c}^{\prime}\right)$. Similarly, 1,4-dibromobenzene (8a) can be converted into 1,4-dibromo-2-(trimethylsilyl)benzene $(\mathbf{8 c})$ and

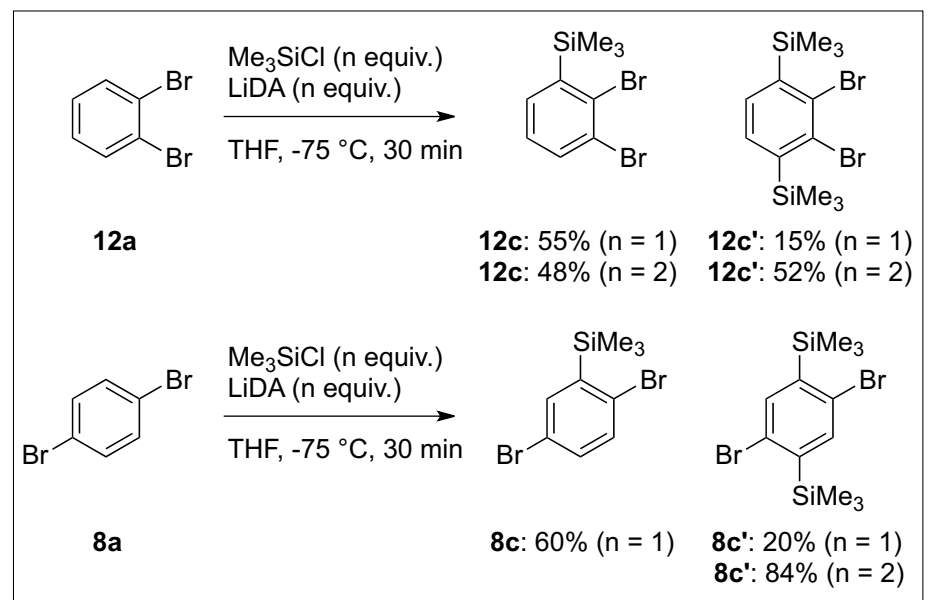

position to be observed. When combined with chlorotrimethylsilane as in situ trap, LiTMP proves a better alternative than LiDA, and the best results are noted using 2 equiv. of each (Scheme 7). [21]

Experiments performed at $-75^{\circ} \mathrm{C}$ under irreversible conditions using LiTMP as base and chlorotrimethylsilane as in situ trap lead to the relative reaction rates (kinetic acidities) of different substituted benzenes (Table 2). ${ }^{[2]}$ Even if it is less pronounced here at the transition state (kinetic) than at the ground state (thermodynamic), bromine (and it is quite similar for chlorine and iodine) enhances the proton mobility more strongly than fluorine and methoxy do when located at the meta and para position.

As a consequence, using LiDA in the presence of chlorotrimethylsilane (2 equiv. each) in THF at $-70{ }^{\circ} \mathrm{C}$ with 1-bromo4-fluorobenzene (5a) furnishes 5-bromo2-fluoro-1,3-bis(trimethylsilyl)benzene (5c) in high yield (Scheme 8). [22]

When bromobenzenes are ortho-substituted by bulky trialkylsilyl groups (e.g. in the case of 17a), the bromo group is less capable of inducing lithiation at the neighboring position due to a buttressing effect. ${ }^{[23]}$ In this case, metalation no longer takes place at the halogen-adjacent posi-

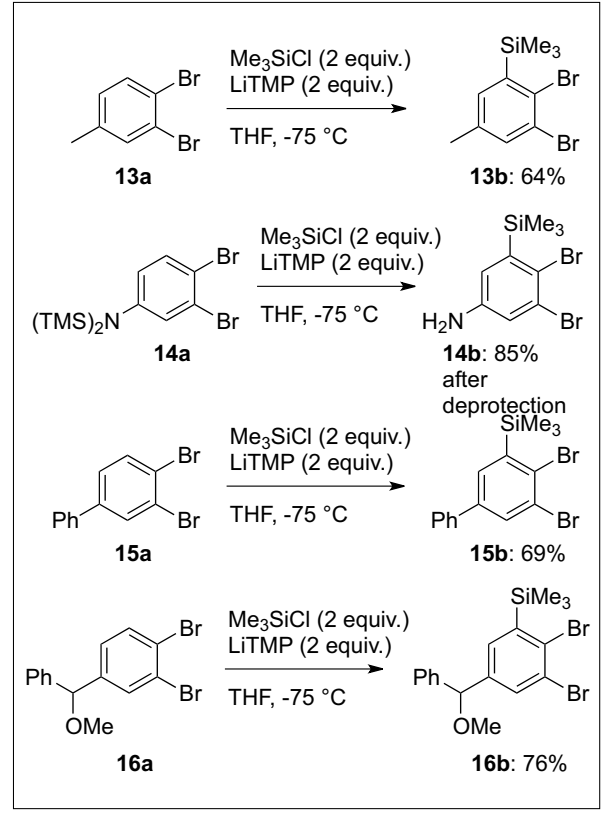

Scheme 7. Deprotolithiation of 4-substituted 1,2-dibromobenzenes using in situ trapping.

Concerning 1,2-dibromobenzene (12a) (or 1-bromo-2-chlorobenzene), such a deprotolithiation using hindered lithium dialkylamides takes place, but 2,3-dibromophenyllithium (or 2-bromo3-chlorophenyllithium/3-bromo-2-chlorophenyllithium) easily rearranges through bromine migration into thermodynamically more stable 2,6-dibromophenyllithium (or 2-bromo-6-chlorophenyllithium). [13,17,20] It is possible to avoid this rearrangement
Table 2. Substituent effects on the free activation energies (reaction with LiTMP in the presence of $\mathrm{Me}_{3} \mathrm{SiCl}$ at $\left.-75^{\circ} \mathrm{C}\right) ; \Delta \Delta \mathrm{G}^{\ddagger}\left(\mathrm{kcal} \mathrm{mol}^{-1}\right)=0.9067 \times\left(\lg k_{\mathrm{x}}-\lg k_{\mathrm{H}}\right)$.

\begin{tabular}{|l|l|l|l|}
\hline $\mathrm{X}$ & & & \\
\hline
\end{tabular}

1,4-dibromo-2,5-bis(trimethylsilyl)benzene (8c') (Scheme 6). ${ }^{[20]}$

In the case of the 1,2-dibromobenzenes 13a-16a, the presence of bulky substituents at the ring 4 position allows a monosilylation at the sterically less congested tion, but solely at the halogen-remote meta position owing to the long-range acidifying effect of the heavy halogen (Scheme 9). [24]

Besides chlorotrimethylsilane, it is possible to intercept arylmetal species generated by deprotonative metalation through

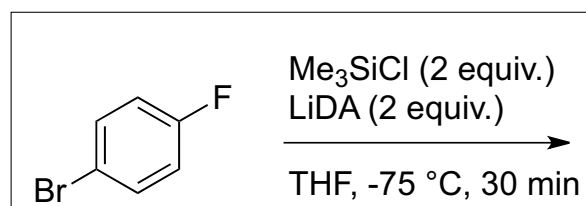

$5 a$<smiles>CCCSc1cc(Br)cc(SC)c1F</smiles>

5c: $78 \%$
Scheme 8.

Consecutive deprotolithiation-silylations of 1-bromo-4-fluorobenzene using in situ trapping. 

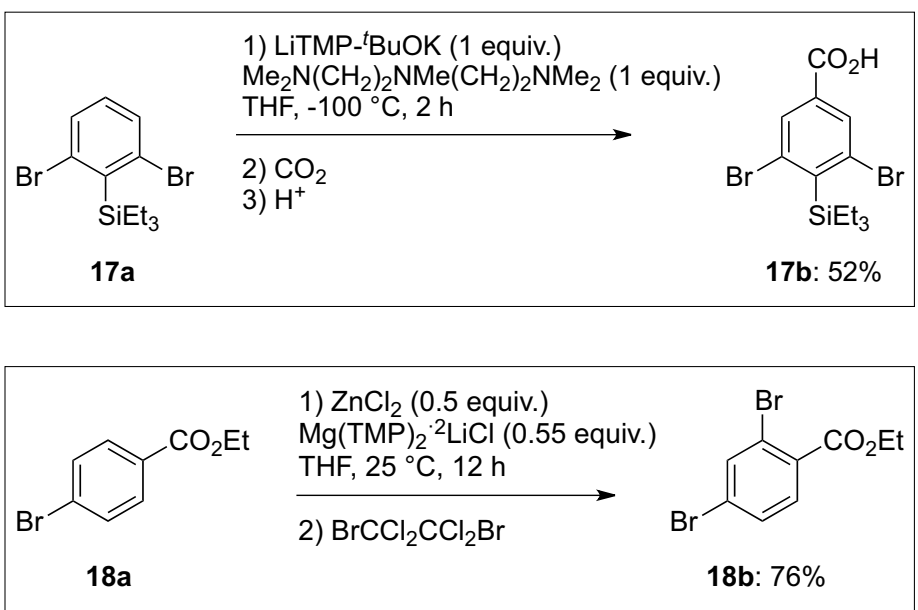

Scheme 9. Reaction showing the longrange acidifying effect of bromine.

Scheme 10.

Deprotometalation of ethyl 4-bromobenzoate. transmetalation. Thus, aromatic compounds bearing sensitive groups such as 18a were functionalized through a deprotometalation step using $\mathrm{Mg}(\mathrm{TMP}) \cdot 2 \mathrm{LiCl}$ in the presence of $\mathrm{ZnCl}_{2}$ (Scheme 10). [24]

\section{Long-range Effect of Bromine in the Deprotometalation of Aromatic Heterocycles}

The most convincing example of the long-range effect of bromine in the de- dered magnesium amides in THF at lower temperatures (Scheme 11).[28]

From 2-bromopyridine (20a), proton abstraction at the 4 or 6 position ('meta' to the bromo group) is described in some cases. Thus, even if the 3-functionalized derivative is the main product, the 4-silylated compound also forms when 2-bromopyridine (20a) is submitted to the action of LiDA in THF at $-75^{\circ} \mathrm{C}$ in the presence of chlorotrimethylsilane (in situ trapping). [29] More importantly, if THF is replaced by

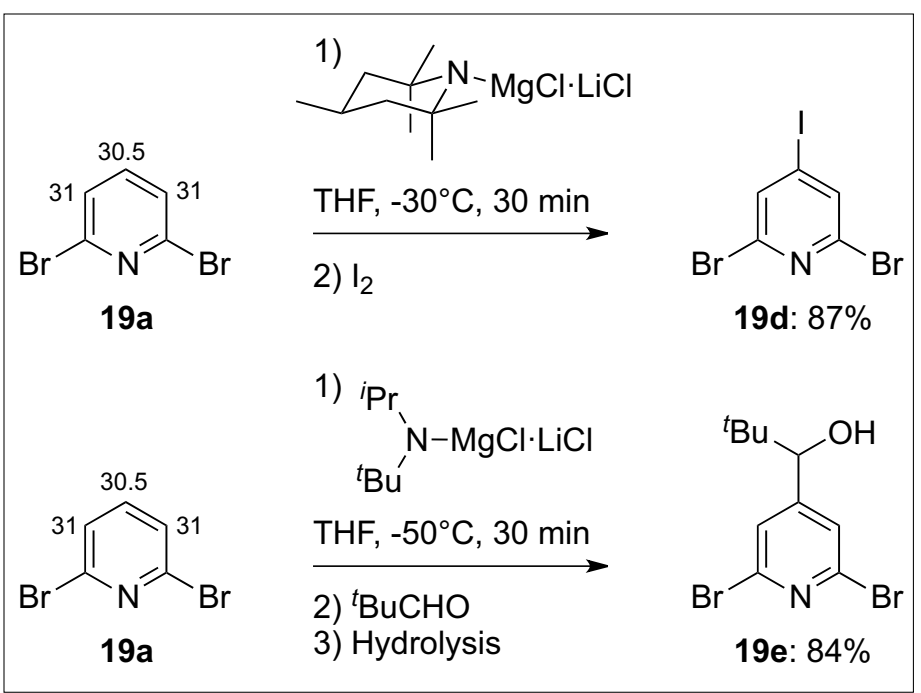

Scheme 11. Calculated $\mathrm{pK}$ (THF) values and deprotometalation of 2,6-dibromopyridine.

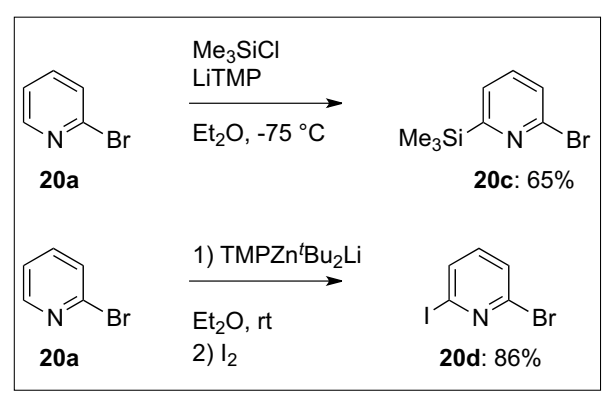

Scheme 12. Deprotometalation of 2-bromopyridine in $\mathrm{Et}_{2} \mathrm{O}$.

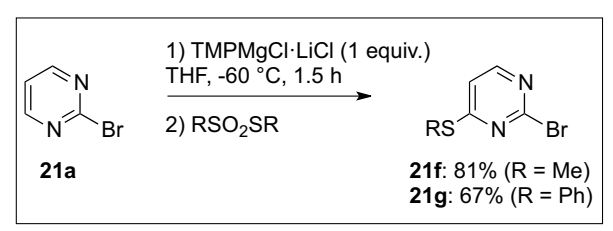

Scheme 13. Deprotometalation of 2-bromopyrimidine.

diethyl ether, the reaction also occurs at a position 'meta' to the bromo group, but this time at the 6 position of the pyridine ring. A similar result also takes place using TMP-zincate $\left({ }^{t} \mathrm{Bu}_{2} \mathrm{Zn}(\mathrm{TMP}) \mathrm{Li}\right)$ in this less coordinating solvent (Scheme 12). [30]

Bromine also plays an important role in the deprotometalation of 2-bromopyrimidine (21a), a substrate prone to nucleophilic attacks, using a LiCl-activated hindered magnesium amide. The heteroarylmetal species can be accumulated in THF at $-60{ }^{\circ} \mathrm{C}$ without degradation, as shown by its quenching after 1.5 hours (Scheme 13). [31]

\section{Conclusions}

Thus, compared with other substituents such as fluorine and methoxy, bromine exhibits a different behavior by acidifying differently the aromatic hydrogens of the ring to which it is connected. Whereas fluorine and methoxy tend to acidify the protonative metalation of pyridines is possibly the reaction of 2,6-dibromopyridine (19a) with hindered metal amides. Upon treatment at room temperature for 2 hours with the base in situ prepared in THF from $\mathrm{ZnCl}_{2} \cdot$ TMEDA ( 0.5 equiv.) and LiTMP (1.5 equiv.), ${ }^{[25]}$ and postulated to be 1:1 LiTMP-Zn(TMP), ( \pm TMEDA), [26] 2,6-dibromopyridine (19a) is attacked at its 4 position. The 4 -iodo derivative $19 d$ is isolated in $87 \%$ yield after iodolysis. The regioselectivity corresponds to combined acidifying and congesting effects of the bromo groups.[27] A clean C(4) deprotonation of 2,6-dibromopyridine (19a) can be performed by using $\mathrm{LiCl}$-activated hin-
Table 3. Substituent effects on the rates of benzyne formation from ortho-, meta-, and para-substituted bromobenzenes $\left(k_{\text {rel, }}\right.$, relative to bromobenzene for which $\left.k_{\text {rel }}=1\right)$.
$\mathrm{X}$

\section{Br}

$\mathrm{F}$

$\mathrm{OMe}$

$\mathrm{NMe}_{2}$

$\mathrm{Ph}$

$\mathrm{Me}$

${ }^{i} \mathrm{Pr}$<smiles>[X]c1ccccc1Br</smiles>

140

34

1.4

0.58

1.9

0.50

0.37<smiles>[X]c1cccc(Br)c1</smiles>

940

1700

600

7.3

1.8

0.35

0.19<smiles>[X]c1ccc(Br)cc1</smiles>

83

25

1.2

0.23

2.0

0.45

0.53 
neighboring hydrogens, bromine exhibits an acidifying effect at a longer range. If we consider the relative rates of formation of benzyne (obtained from haloarenes upon treatment by lithium piperidide in diethyl ether ${ }^{[32]}$ as a measure of the 2-haloaryl stability, ${ }^{[33]}$ we can once more evidence this behavior at the origin of numerous functionalizations (Table 3).

Received: April 10, 2015

[1] a) H. W. Gschwend, H. R. Rodriguez, Org. React. 1979, 26, 1; b) P. Beak, V. Snieckus, Acc. Chem. Res. 1982, 15, 306; c) V. Snieckus, Chem. Rev. 1990, 90, 879; d) T. G. Gant, A. I. Meyers, Tetrahedron 1994, 50, 2297; e) M. Schlosser, in 'Organometallics in Synthesis', $2^{\text {nd }}$ ed., Ed. M. Schlosser, Chap. I, 2002.

[2] F. Mongin, C. Curty, E. Marzi, F. R. Leroux, M. Schlosser, ARKIVOC 2015, 48

[3] M. Uchiyama, T. Miyoshi, Y. Kajihara, T. Sakamoto, Y. Otani, T. Ohwada, Y. Kondo, $J$. Am. Chem. Soc. 2002, 124, 8514.

[4] T. D. Krizan, J. C. Martin, J. Am. Chem. Soc. 1983, 105, 6155 .

[5] F. Mongin, O. Desponds, M. Schlosser, Tetrahedron Lett. 1996, 37, 2767.

[6] Concerning long-range effects in deprotonative lithiation, see: T. Kliś, S. Luliński, J. Serwatowski, Curr. Org. Chem. 2008, 12, 1479.
[7] E. Castagnetti, M. Schlosser, Chem. Eur. J. 2002, 8, 799 .

[8] a) F. Faigl, E. Marzi, M. Schlosser, Chem. Eur. J. 2000, 6, 771. See also: b) I. Hyla-Kryspin, S. Grimme, H. H. Büker, N. M. M. Nibbering, F. Cottet, M. Schlosser, Chem. Eur. J. 2005, 11, 1251.

[9] F. Mongin, M. Schlosser, unpublished results.

[10] F. Mongin, M. Schlosser, Tetrahedron Lett. 1996, 37,6551

[11] a) J. Moyroud, J.-L. Guesnet, B. Bennetau, J. Mortier, Tetrahedron Lett. 1995, 36, 881; b) J. Moyroud, J.-L. Guesnet, B. Bennetau, J. Mortier, Bull. Soc. Chim. Fr. 1996, 133, 133.

[12] A. J. Bridges, A. Lee, E. C. Maduakor, C. E. Schwartz, Tetrahedron Lett. 1992, 33, 7495.

[13] F. Mongin, M. Schlosser, Tetrahedron Lett. 1997, 38,1559

[14] 2-Chlorobenzoic acid is isolated in $21 \%$ yield using LiTMP ( 1 equiv.) at $-75{ }^{\circ} \mathrm{C}$ for 2 hours, in $43 \%$ yield using LiTMP ( 2 equiv.) at $-75^{\circ} \mathrm{C}$ for 2 hours, $45 \%$ yield using LiTMP ( 2 equiv.) at $-75{ }^{\circ} \mathrm{C}$ for 6 hours.

[15] 2-Bromophenyltrimethylsilane can be obtained in about $40 \%$ yield, but using 10 equiv. of LiTMP at $-75^{\circ} \mathrm{C}$ in the presence of chlorotrimethylsilane as in situ trap.

[16] See also: J. Gorecka-Kobylinska, M. Schlosser, J. Org. Chem. 2009, 74, 222.

[17] F. Mongin, E. Marzi, M. Schlosser, Eur. J. Org. Chem. 2001, 2771.

[18] S. Luliński, J. Serwatowski, M. Szczerbińska, Eur. J. Org. Chem. 2008, 1797.

[19] a) M. Dąbrowski, J. Kubicka, S. Luliński, J. Serwatowski, Tetrahedron Lett. 2005, 46, 4175. See also: b) S. Luliński, J. Serwatowski, A. Zaczek, Eur. J. Org. Chem. 2006, 5167.
[20] S. Luliński, J. Serwatowski, J. Org. Chem. 2003, 68,5384

[21] V. Diemer, F. R. Leroux, F. Colobert, Eur. J. Org. Chem. 2011, 327.

[22] S. Luliński, J. Serwatowski, J. Org. Chem. 2003, 68, 9384 .

[23] M. Decouzon, P. Ertl, O. Exner, J.-F. Gal, P.-C. Maria, J. Am. Chem. Soc. 1993, 115, 12071.

[24] C. Heiss, E. Marzi, M. Schlosser, Eur. J. Org. Chem. 2003, 4625 .

[25] J. M. L'Helgoual'ch, A. Seggio, F. Chevallier, M. Yonehara, E. Jeanneau, M. Uchiyama, F. Mongin, J. Org. Chem. 2008, 73, 177.

[26] P. García-Álvarez, R. E. Mulvey, J. A. Parkinson, Angew. Chem. Int. Ed. 2011, 50, 9668.

[27] K. Snégaroff, T. T. Nguyen, N. Marquise, Y. S. Halauko, P. J. Harford, T. Roisnel, V. E. Matulis, O. A. Ivashkevich, F. Chevallier, A. E. H. Wheatley, P. C. Gros, F. Mongin, Chem. Eur. J. 2011, 17, 13284 .

[28] C. J. Rohbogner, S. H. Wunderlich, G. C. Clososki, P. Knochel, Eur. J. Org. Chem. 2009, 1781

[29] a) F. Effenberger, W. Daub, Chem. Ber. 1991, 124, 2119; b) G. W. Gribble, M. G. Saulnier, Tetrahedron Lett. 1980, 21, 4137.

[30] T. Imahori, M. Uchiyama, T. Sakamoto, Y. Kondo, Chem. Commun. 2001, 2450.

[31] M. Mosrin, P. Knochel, Org. Lett. 2008, 10, 2497.

[32] R. Huisgen, W. Mack, K. Herbig, N. Ott, E. Anneser, Chem. Ber. 1960, 93, 412.

[33] M. Schlosser, Angew. Chem. Int. Ed. 1998, 37, 1496. 